\title{
Boundary layer dynamics over London, UK, as observed using Doppler lidar during REPARTEE-II
}

\author{
J. F. Barlow ${ }^{1}$, T. M. Dunbar ${ }^{1}$, E. G. Nemitz ${ }^{2}$, C. R. Wood ${ }^{1}$, M. W. Gallagher ${ }^{3}$, F. Davies ${ }^{4,{ }^{*}}$, E. O'Connor ${ }^{1,6}$, and \\ R. M. Harrison ${ }^{5}$ \\ ${ }^{1}$ Department of Meteorology, University of Reading, P.O. Box 243, Reading, RG6 6BB, UK \\ ${ }^{2}$ Centre for Ecology and Hydrology (Edinburgh), Bush Estate, Penicuik, EH260QB, UK \\ ${ }^{3}$ School of Earth, Atmospheric and Environmental Sciences, University of Manchester, Williamson Building, Oxford Road, \\ Manchester, M13 9PL, UK \\ ${ }^{4}$ Room 315 Peel Building, University of Salford, The Crescent, Greater Manchester, M5 4WT, UK \\ ${ }^{5}$ School of Geography, Earth and Environmental Sciences, University of Birmingham, Birmingham, B15 2TT, UK \\ ${ }^{6}$ Finnish Meteorological Institute, P.O. Box 503, 00101 Helsinki, Finland \\ *currently at: School of Earth and Environment, Maths/Earth and Environment Building, University of Leeds, \\ Leeds, LS2 9JT, UK
}

Received: 30 April 2010 - Published in Atmos. Chem. Phys. Discuss.: 24 August 2010

Revised: 20 December 2010 - Accepted: 2 February 2011 - Published: 9 March 2011

\begin{abstract}
Urban boundary layers (UBLs) can be highly complex due to the heterogeneous roughness and heating of the surface, particularly at night. Due to a general lack of observations, it is not clear whether canonical models of boundary layer mixing are appropriate in modelling air quality in urban areas. This paper reports Doppler lidar observations of turbulence profiles in the centre of London, UK, as part of the second REPARTEE campaign in autumn 2007. Lidar-measured standard deviation of vertical velocity averaged over $30 \mathrm{~min}$ intervals generally compared well with in situ sonic anemometer measurements at $190 \mathrm{~m}$ on the BT telecommunications Tower. During calm, nocturnal periods, the lidar underestimated turbulent mixing due mainly to limited sampling rate. Mixing height derived from the turbulence, and aerosol layer height from the backscatter profiles, showed similar diurnal cycles ranging from c. 300 to $800 \mathrm{~m}$, increasing to c. 200 to $850 \mathrm{~m}$ under clear skies. The aerosol layer height was sometimes significantly different to the mixing height, particularly at night under clear skies. For convective and neutral cases, the scaled turbulence profiles resembled canonical results; this was less clear for the stable case. Lidar observations clearly showed enhanced mixing beneath stratocumulus clouds reaching down on occasion to approximately half daytime boundary layer depth. On
\end{abstract}

Correspondence to: J. F. Barlow

(j.f.barlow@ reading.ac.uk) one occasion the nocturnal turbulent structure was consistent with a nocturnal jet, suggesting a stable layer. Given the general agreement between observations and canonical turbulence profiles, mixing timescales were calculated for passive scalars released at street level to reach the BT Tower using existing models of turbulent mixing. It was estimated to take c. $10 \mathrm{~min}$ to diffuse up to $190 \mathrm{~m}$, rising to between 20 and $50 \mathrm{~min}$ at night, depending on stability. Determination of mixing timescales is important when comparing to physicochemical processes acting on pollutant species measured simultaneously at both the ground and at the BT Tower during the campaign. From the 3 week autumnal data-set there is evidence for occasional stable layers in central London, effectively decoupling surface emissions from air aloft.

\section{Introduction}

Understanding urban boundary layer (UBL) dynamics is particularly important for accurate modelling of air quality. Due to the difficulties in making observations in urban areas, ground-based remote sensing is becoming more important in elucidating complex UBL structure. In addition observations of the impact of vertical dispersion in the urban boundary layer on gases and aerosols are relatively rare. Here we report detailed Doppler lidar observations of central London's UBL structure. Observations are evaluated using in situ turbulence

Published by Copernicus Publications on behalf of the European Geosciences Union. 
measurements, compared to canonical BL results, and estimates are made of timescales for turbulent transport from street level to the top of a $190 \mathrm{~m}$ tall tower, the "BT Tower".

One question is whether UBL turbulence structure is significantly different to results obtained over extensive rural surfaces. Roth (2000) reviewed mainly ground-based observations of urban turbulence characteristics, concluding that there was a general agreement with similarity theories for the urban surface layer, but due to lack of data, behaviour of the urban boundary layer above this was poorly understood. Various studies have used tall towers and found broad agreement with locally scaled similarity relationships, particularly for complex terrain (Al-jiboori (2002), Beijing; Vesala et al. (2008), Helsinki). Wood et al (2010) found similar behaviour, but also estimated boundary layer height using turbulence measurements on the $190 \mathrm{~m}$ BT Tower in London to test mixed layer scaling. Han et al. (2009) used a $250 \mathrm{~m}$ Tower in Tianjin to relate nocturnal pollutant levels to mixing height $(\mathrm{MH})$ dynamics. Despite the micrometeorological advantage of such high level measurements to assess large-scale urban footprints, simultaneous observation of all heights of the UBL is generally lacking - and given the potential complexities of UBL structure, this is particularly desirable.

In terms of pollution levels, mixing height is an important controlling factor. Seibert (2000) reviewed methods for determining mixing height with respect to modelling air pollution as part of the COST action 710. Remote sensing methods prove particularly useful for deriving urban mixing heights, being generally easier to deploy than masts, radiosondes (Georgoulias 2009, Thessaloniki) or tethered balloons, but require appropriate algorithms to derive the mixing height (Emeis, 2008). In urban areas, various methods have been used, including sodar (Spanton and Williams, 1992, London); Emeis and Turk, 2004, Hannover), lidar (He et al., 2006, Beijing; Davies et al., 2007, London; Chen et al., 2001, Tsukuba) or a combination of methods including Radio Acoustic Sounding System (RASS), ceilometers, wind profiles and radar (Dupont et al., 1999, Paris; Angevine et al., 2003, Nashville; Emeis et al., 2004, Hannover). Generally it has been found that the UBL is deeper than the surrounding rural boundary layer (Angevine et al., 2003; Davies et al., 2007; Dupont et al., 1999).

Remote sensing is particularly useful in analysing vertical profiles of turbulent mixing in the UBL. Emeis et al. (2004), Emeis et al. (2007) and Barlow et al. (2008) used acoustic remote sensing to derive wind profiles and noted the sensitivity of the profile to underlying roughness which can be highly heterogeneous in urban areas. Use of dual Doppler lidars (Collier et al., 2005; Newsom et al., 2005; Davies et al., 2007) can improve the accuracy in derived wind profiles and provide dense networks of "virtual towers" (Calhoun et al., 2006, Oklahoma City), especially useful if the urban windfield is complex due to e.g. tall buildings or changing landuse. Argentini et al. (1999) studied convection driven by the relative warmth of Milan during winter-time inversion conditions and scaled the results using similarity theory. More complex flow conditions over urban areas due to combined effects of the city and inversions forming in mountainous terrain have been studied using arrays of sodars (Piringer et al, 2001, Graz) and Doppler lidar (Darby et al., 2006, Salt Lake City).

The nocturnal urban boundary layer is particularly complex due to the urban heat island (UHI) delaying surface cooling. Uno et al. (1992) observed a near-neutral groundbased layer with an elevated inversion layer at night-time over Sapporo. Casadio et al. (1996) observed nocturnal convective activity using a Doppler sodar over Rome, presumed to be due to the combination of the UHI and cold air advection by sea breezes over the warm urban surface. Using similar equipment, Rao et al. (2002) combined Doppler sodar and Raman lidar water vapour data to estimate water vapour flux profiles over Rome over several nights. Particularly large fluxes were also observed due to sea breeze advection. Daytime sea breeze interactions with the UBL have been studied using combinations of model and remote sensing observations (Liu et al., 2001, Hong Kong; Ferretti et al., 2003, Rome). Lemonsu et al. (2006) found that the sea breeze, modulated by local topography, dominated over the influence of urban surface energy balance in determining boundary layer structure over Marseille.

The UHI also interacts with other mesoscale features at night (e.g. regional Low Level Jets (LLJ), and mountain drainage currents). The strong regionally formed Low Level Jet of the US mid-west was observed using Doppler sodar over Oklahoma City (Klein and Clark, 2007). Kallistratova et al. (2009) used Doppler sodars to observe that the nocturnal jets over Moscow were less frequent, and higher in the atmosphere than the nearby rural area. The role of katabatic flows due to the surrounding mountains in forming the jets was acknowledged. Kolev et al. (2000, Sofia), Piringer et al., (2001, Graz) and Darby et al. (2006, Salt Lake City) all observed complex vertical and spatial structures in nocturnal UBLs influenced by local mountainous topography.

There have been many campaigns to investigate the influence of the UBL on pollutant levels using combinations of remote sensing techniques (e.g. MEDCAPHOT-TRACE in Athens, Ziomas 1998; ECLAP in Paris, Dupont et al., 1999; ESQUIF in Paris, Menut et al., 2000; ESCOMPTE in Marseille, Cros et al., 2004 in parallel with UBL/CLU in Marseille, Mestayer et al., 2005). Banta et al. (1998) used aeroplane based Differential Absorption Lidar (DIAL) to observe ozone distributions over Nashville, combining them with ground-based wind profiler observations of boundary layer structure. Reitebuch et al. (2000) used Doppler sodar profiles to observe the impact of a nocturnal jet and frontal passage on ozone concentrations in Essen. Lidar has been used to observe the vertical structure of particulates (Cooper and Eichinger 1994, Mexico City; Vakeva et al., 2000; Guinot et al., 2006, Beijing). A lidar operating at 
wavelengths 532-1064 nm allowed Del Guasta et al. (2002) to note the correlation between aerosol mass and UBL dynamics over Florence.

The objectives of this paper are threefold: (1) to compare the Doppler lidar with in situ Tower turbulence observations, in order to evaluate its performance (2) to test whether the turbulent structure of the boundary layer over a large urban area is significantly different to canonical models, and (3) to estimate the impact of variability in turbulent structure on mixing timescales for surface-released passive scalars. This work was undertaken as part of the REPARTEE project to investigate the chemical and dynamical processes affecting urban pollutant variability, which took place between October 2006 and November 2007 (Harrison et al., 2011). The paper focuses on Doppler lidar data collected during the second Intensive Observation Period (IOP) in autumn 2007.

\section{Campaign overview}

\subsection{Sites and instrumentation}

The REPARTEE 2007 campaign ran from 15 October to 15 November 2007 and the experimental aim, sites and apparatus are fully described in Harrison et al. (2011). This paper reports only on results using the meteorological instrumentation which is described here.

A 3 axis ultrasonic anemometer (R3-50, Gill Instruments, UK) and weather station (Vaisala WXT510) were installed on top of the BT Tower (lat. $51^{\circ} 31^{\prime} 17.31^{\prime \prime} \mathrm{N}$, lon. $0^{\circ} 8^{\prime}$ 20.12" W), as first reported in Wood et al. (2010). The Tower is located approximately $1.2 \mathrm{~km}$ to the east of the lidar site as shown in Fig. 1 and is the tallest building within several kilometres of the site, with good exposure to winds in all directions. The anemometer was mounted at the top of an open lattice square scaffolding tower of $12.2 \mathrm{~m}$ height on a $1.5 \mathrm{~m}$ boom at the southerly corner. The lattice is situated on top of the main building structure, the top section of which has a diameter of $14.8 \mathrm{~m}$. This resulted in a measurement height of $190.3 \mathrm{~m}$, or approximately 9 times local mean building height (Barlow et al., 2009). Gas and particulate sampling co-located with the meteorological measurements are reported in other papers in this special issue. Data from the sonic anemometer were logged at $20 \mathrm{~Hz}$ and were subject to quality assurance checks (see Wood et al., 2010 for details). The data showed a small upward deflection (mean value $5.8^{\circ}$ ), but little variation in turbulent intensity with direction (Barlow et al., 2009), indicating a small amount of flow distortion around the tower. The data were rotated into the mean wind direction using the double-rotation method (Wilczak et al. 2001) prior to flux density calculation.

A pulsed Doppler lidar (HALO Photonics), housed in a van, was located in a basement level car park at the University of Westminster (lat. $51^{\circ} 31^{\prime} 19.86^{\prime \prime} \mathrm{N}$, lon. $0^{\circ} 9^{\prime}$ $21.58^{\prime \prime} \mathrm{W}$ ) The lidar beam was emitted within $1 \mathrm{~m}$ of street

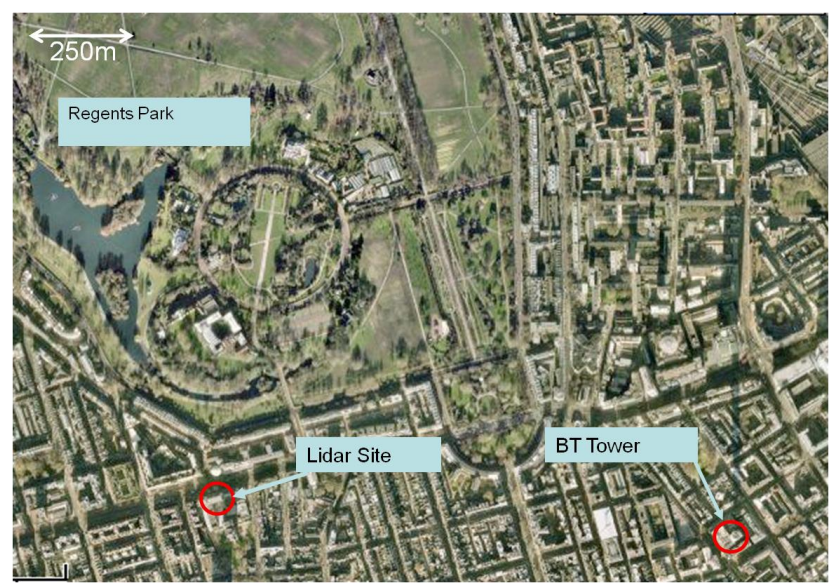

Fig. 1. Site of Doppler lidar and BT Tower sonic anemometer during the REPARTEE campaign in central London, UK, in October/November 2007.

level. Two modes of operation were used: continuous vertical stare, and three-beam line of site to derive wind profiles every $30 \mathrm{~min}$ (Pearson et al., 2009). This paper concerns the vertical stare data only and more detail on lidar characteristics is given in Sect. 3. The general area was characterised by commercial and residential buildings: near the Marylebone Road the mean building height is $21 \mathrm{~m}$, plan area density is 0.4 (Barlow et al., 2009), whereas the source area for the BT Tower generally lies between 1 and $10 \mathrm{~km}$ distance, in which the mean building height is $9 \mathrm{~m}$ (Wood et al., 2010).

\subsection{Meteorological overview}

Hourly averages were computed of meteorological variables recorded by the weather station on the BT Tower at $190 \mathrm{~m}$. Figure 2a shows the normalised frequency distribution of wind direction and mean sector wind-speed based on hourly averages for the entire campaign. Winds were predominantly from the westerly sector. Mean wind-speed for the campaign was $6.8 \mathrm{~m} \mathrm{~s}^{-1}$.

Figure $2 \mathrm{~b}$ shows the time series of pressure, dry bulb temperature and relative humidity for the entire campaign - note the diurnal temperature and humidity range experienced at the Tower, and also that given the Tower height, temperatures and pressures at the surface are likely to be approximately $2{ }^{\circ} \mathrm{C}$ and $20 \mathrm{hPa}$ higher respectively. All times are UTC throughout this paper. October and November 2007 were more anti-cyclonic than normal for the UK (Met Office) with two periods of high pressure during the campaign (18 to 26 October; 1 to 7 November; see Fig. 2b). Other days were characterised by frontal activity bringing rain. During the 432 hourly periods when the lidar was in operation, the state of the atmosphere was characterized by visual inspection of the lidar data (see Fig. 4 for examples) as well as consideration of pressure tendency. The lidar shows cloud at 

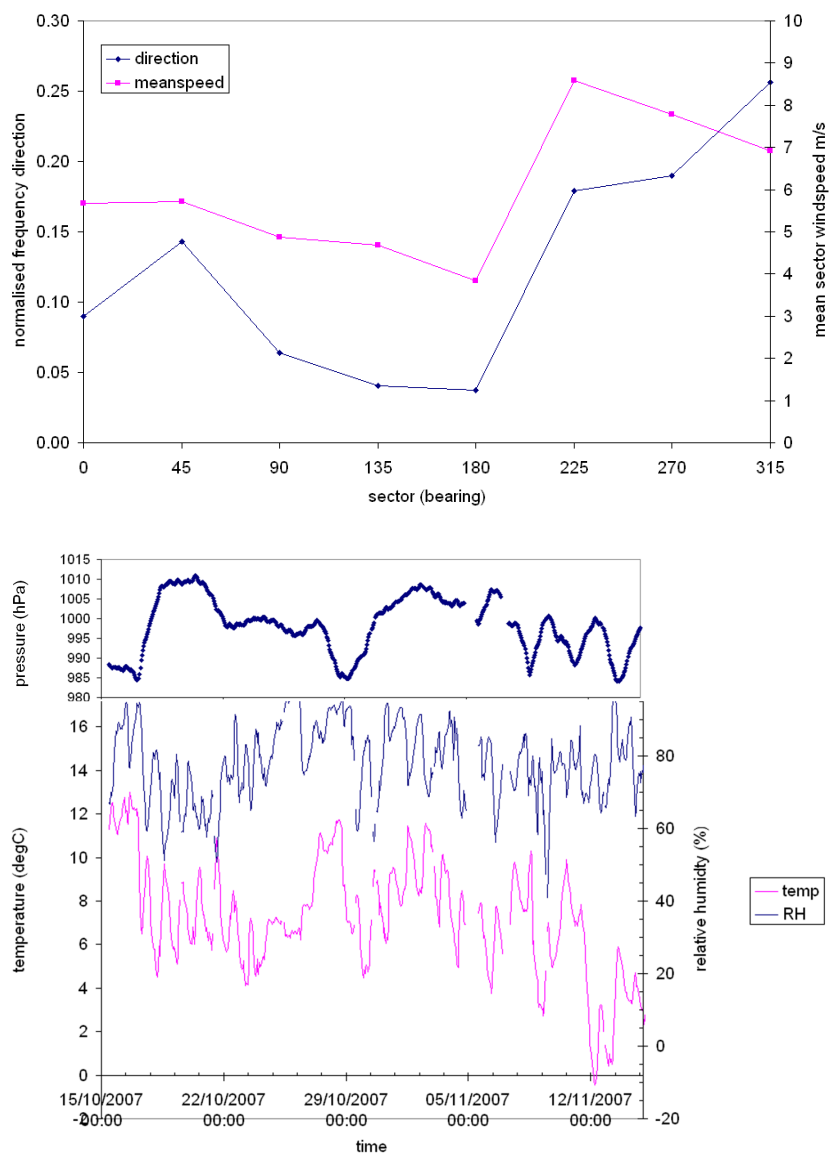

Fig. 2. Meteorological data measured using Vaisala WXT510 weather station at BT Tower during REPARTEE II. (a) Mean windspeed and direction frequency data per $45^{\circ}$ sector. (b) Time series of temperature, relative humidity and pressure data for BT Tower.

the top of the boundary layer as high backscatter; and rain as high backscatter with downward Doppler velocity component of order $1 \mathrm{~m} \mathrm{~s}^{-1}$ in magnitude. Table 1 shows the result of classification into categories: rain and/or frontal activity; day-time or night-time cloud; day-time or night-time "clear". Higher level clouds not detected by the lidar will also have an influence on surface heating, but the structure of the boundary layer is determined more strongly by lower level, stratiform clouds (e.g. Lock et al., 2000). The number of "clear sky" periods was relatively high due to the dominance of high pressure periods, and of particular interest was the exceptionally large number of "clear sky" overnight periods to assess the nocturnal radiation budget and its influence on turbulence structure. As night-time boundary layer behaviour in urban areas is less well studied, this data-set provides an opportunity to analyse this in some detail.

The turbulent flux measurements from the sonic anemometer were averaged over $30 \mathrm{~min}$ periods. For the BT Tower site, during autumn periods in 2006 and 2007, Martin (2009) showed that for particle fluxes an integration
Table 1. Frequency of periods of rain, and cloud cover estimated from lidar data by day and night.

\begin{tabular}{ll}
\hline Classification & Frequency (no. of hours) \\
\hline Rain/frontal activity & 118 \\
Day-time cloud & 46 \\
Night-time cloud & 93 \\
Day-time "clear" & 54 \\
Night-time "clear" & 121 \\
\hline
\end{tabular}

period of $30 \mathrm{~min}$ leads to less than a $10 \%$ underestimate compared to one of $60 \mathrm{~min}$. Helfter et al. (2010) found smaller bias $(<-5 \%)$ over a longer period for the same site, and concluded that $30 \mathrm{~min}$ averaging was a pragmatic choice compromising between capturing all scales of turbulence contributing to fluxes, and sub-diurnal variability. Similar reasoning is used in this study, however, it is acknowledged that for some periods the flux estimates presented here will be subject to a small underestimate.

\section{Doppler lidar observations}

The instrument used during the campaign was a heterodyne, pulsed Doppler lidar (HALO Photonics) which had been previously used at a rural site in southern England (Pearson et al., 2009), a tropical forested site (Pearson et al., 2010) and in Helsinki (Bozier et al 2007). The instrument uses $1.5 \mu \mathrm{m}$ wavelength light of low enough energy to be eye-safe, and so is suitable for use in urban areas - other technical specifications are listed in Table 2. The bias in velocity measurements is reported to be less than $0.02 \mathrm{~m} \mathrm{~s}^{-1}$ (Pearson et al., 2009). The lidar operated for 19 days between 25 October and 13 November 2007 with a gate size of $30 \mathrm{~m}$ and integration time of $3.6 \mathrm{~s}$, giving an effective sampling rate of $0.278 \mathrm{~Hz}$. During the campaign it performed continuous vertical stare measurements of both the backscatter and vertical Doppler velocity component.

To assess accuracy of the velocity estimates the theoretical standard deviation for each measurement given by Rye and Hardesty (1993) was used

$\sigma_{e}=\left(\frac{\Delta v^{2} \sqrt{2}}{\alpha N_{p}}\left(1+1.6 \alpha+0.4 \alpha^{2}\right)\right)^{1 / 2}$,

where $\alpha$ is the ratio of the lidar detector photon count to the speckle count, $\Delta \mathrm{v}$ is the signal spectral width and $N_{p}$ is the accumulated photon count, given by:

$N_{p}=\mathrm{SNR} M n$,

where $M$ is the number of points per range gate and $n$ is the number of pulses averaged. $\alpha$ is given by:

$\alpha=\frac{\mathrm{SNR}}{(2 \pi)^{1 / 2}(\Delta v / B)}$, 
Table 2. Technical specifications of Doppler lidar.

\begin{tabular}{ll}
\hline Wavelength & $1.5 \mu \mathrm{m}$ \\
\hline Pulse repetition frequency & $20 \mathrm{KHz}$ \\
Sampling frequency & $30 \mathrm{MHz}$ \\
Vertical resolution & $30 \mathrm{~m}$ \\
Integration time & $4 \mathrm{~s}$ \\
\hline
\end{tabular}

where $B$ is the receiver bandwidth. In this study, $\sigma_{e}=$ $0.1 \mathrm{~m} \mathrm{~s}^{-1}$ was used as a threshold above which data were rejected, which corresponds to a $S N R \sim-20 \mathrm{~dB}$. Backscatter and vertical velocity variance were then calculated over 30 min averaging periods.

\subsection{Comparison of lidar and sonic anemometer turbulence observations}

Figure 3 shows the standard deviation of vertical velocity, $\sigma_{\text {wlidar }}$, from the lidar gate 7 (180 to $\left.210 \mathrm{~m}\right)$, sampling at $0.278 \mathrm{~Hz}$ plotted against the BT Tower sonic anemometer $\sigma_{\text {wsonic }}$ at $190 \mathrm{~m}$ with sampling frequency $20 \mathrm{~Hz}$, computed over 30 min periods. It can be seen that there is a correlation but with an underestimate in slope (0.82) and considerable scatter $\left(R^{2}=0.77\right)$. At times it was observed that $\sigma_{\text {wlidar }}$ was significantly lower than $\sigma_{\text {wsonic }}$. It was thought that during these periods the turbulence scale is small and thus the sampling rate of the lidar is not high enough to capture all scales of turbulence contributing to the standard deviation. The size of the gate $(30 \mathrm{~m})$ will also limit the scale of eddies which the lidar can capture. To take the limited sampling rate into account, which goes some way to enabling a comparison between the instruments, Fig. 3 also shows the sonic data averaged to match the lidar sampling frequency. The slope has improved as it is closer to the 1:1 line (0.96), whilst the goodness of fit is slightly worse $\left(R^{2}=0.73\right)$, giving confidence that the lidar is producing similar statistics to a point measurement on average. Corrections, such as have been suggested by Hogan et al. (2009) have not been applied to this dataset but the potential underestimate should be noted.

\subsection{Derivation of heights of aerosol layers and mixing height}

Both backscatter and velocity variance data from the lidar were used to determine three different heights pertaining to layers in the atmosphere. The gradient in backscatter $d \beta / d z$ was used to define the Boundary Layer top, $z_{\mathrm{BL}}$, where there is a very large gradient between the free atmosphere which is relatively aerosol free compared with the polluted BL below; and a ground-based aerosol layer depth, $z$ AER, determined by the first exceedance of the threshold value of backscatter gradient looking from the ground upwards $\left(-4 \times 10^{-9} \mathrm{~m}^{-2} \mathrm{sr}^{-1}\right)$. The mixing height, $z_{\mathrm{MH}}$, was defined

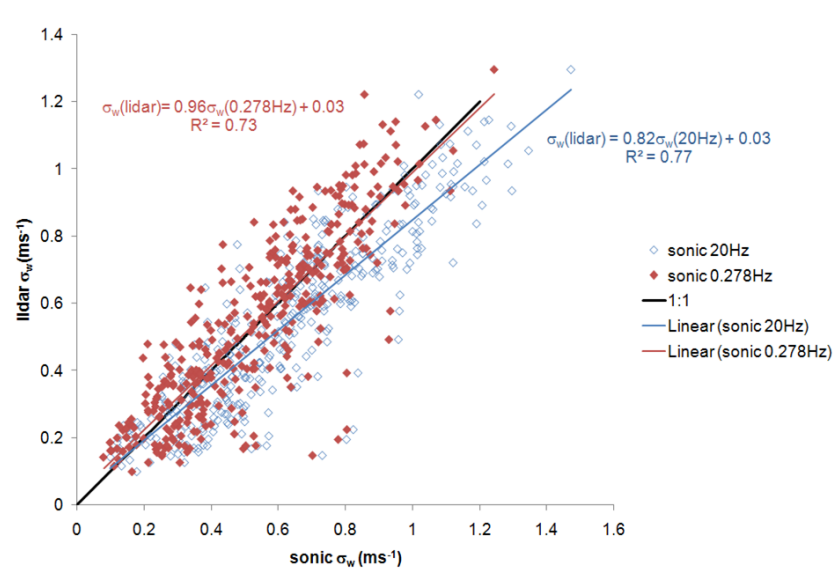

Fig. 3. Scatterplot of standard deviation of vertical velocity $\sigma_{w}$ measured by lidar against sonic anemometer $\sigma_{w}$ sampled at $20 \mathrm{~Hz}$ and averaged to $0.278 \mathrm{~Hz}$.

as the height up to which a threshold of $\sigma_{w}^{2}>0.1 \mathrm{~m}^{2} \mathrm{~s}^{-2}$ was met.

Both thresholds were determined qualitatively by assessing whether the magnitude and diurnal cycle of layer heights were physically realistic and reasonably consistent from one period to the next. In comparison, Pearson et al. (2010) used $\sigma_{w}^{2}>0.3 \mathrm{~m}^{2} \mathrm{~s}^{-2}$ and first minimum in backscatter gradient for a highly convective, tropical boundary layer. As it is recognized that the thresholds chosen are a little arbitrary (and probably depend on the aerosol loading), the sensitivity of derived heights to threshold criterion was tested. Given a $10 \%$ perturbation in the threshold criterion for $z_{\mathrm{MH}}, 72 \%$ of the values of $z_{\mathrm{MH}}$ over all 1824 periods did not change; $22 \%$ changed by 1 gate, and $6 \%$ by 2 gates or more. Similarly, for a $10 \%$ perturbation in the threshold criterion for $z_{\mathrm{AER}}$, $83 \%$ did not change, $7 \%$ changed by 1 gate, and $9 \%$ changed by 2 gates or more. It was noted that $z$ AER was least sensitive to the perturbation at night, presumably because the lack of mixing sharpens the gradient in aerosol concentration and thus increases backscatter gradient.

\section{Results}

\subsection{Boundary layer characteristic features}

Figure 4 shows time series for 6 and 7 November 2007 of 1 min averages of lidar data: attenuated backscatter, vertical Doppler velocity, and vertical velocity variance, $\sigma_{w}^{2}$. These days were chosen as being rain-free, with no frontal activity influencing boundary layer state. Overlaid on the backscatter plots are estimates of aerosol layer heights, and on the variance plots the mixing height is shown, all calculated according to the methods in Sect. 3.2. The height of the BT Tower is shown by a horizontal dashed line. 

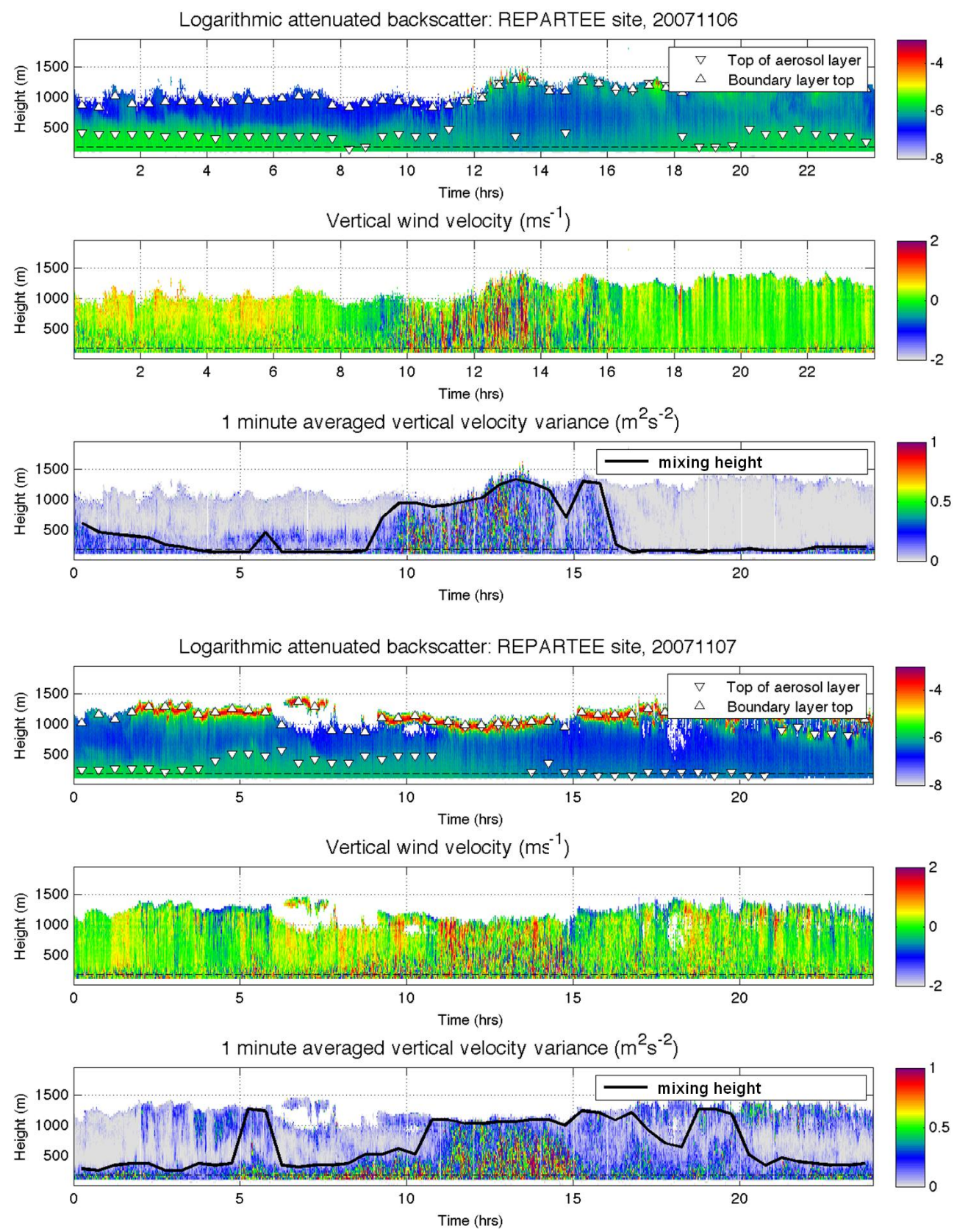

Fig. 4. Doppler lidar observations of backscatter $\beta\left(\mathrm{m}^{-1} \mathrm{sr}^{-1}, \log _{10}\right.$ scale), vertical wind velocity $w\left(\mathrm{~m} \mathrm{~s}^{-1}\right)$ and variance of vertical wind velocity $\sigma_{w}^{2}\left(\mathrm{~m}^{2} \mathrm{~s}^{-2}\right)$. Observations show $1 \mathrm{~min}$ averages of $0.278 \mathrm{~Hz}$ data. Derived heights of boundary layer top, aerosol layer and mixing height are also shown. Height of BT Tower $(190 \mathrm{~m})$ is depicted as dashed line. (a) 6 November 2007, (b) 7 November 2007.

Various boundary layer characteristics are shown in these two days. On 6 November (Fig. 4a) conditions were mostly cloud-free and mean wind-speed was $6.6 \mathrm{~m} \mathrm{~s}^{-1}$, i.e. near campaign average. During the overnight periods (00:00 to 08:00; 21:00 to 24:00 UTC), distinct aerosol layers developed at ground level extending up to approximately $500 \mathrm{~m}$. It is clear that turbulent mixing is confined to a layer near the ground. The Monin-Obukhov stability parameter $z-z_{d} / L$ (where $z_{d} \sim 4.3 \mathrm{~m}$ was estimated for this part of London by
Wood et al., 2010) was determined locally at the BT Tower at $190 \mathrm{~m}$ and increased steadily from approximately 0.3 to 1.5 between 00:00 and 07:00, showing stable conditions at that height. Hygrosocopic aerosol particles may also have been growing due to increasing relative humidity as the air cooled, leading to enhanced backscatter. After sunrise at 07:01, the aerosol layer broke down at approximately 08:30, as the convective boundary layer started to grow, mixing and diluting aerosols upward through its depth: changes in 
backscatter intensity could also be due to changed particle composition and size distribution, e.g. as traffic and building source activities increased. From the variance time series, it can be seen that the ground based overnight turbulent layer decreased in height, with the development of a band of weak turbulence between c. 300 and $500 \mathrm{~m}$ between 04:30 and 09:00. These signatures may correspond to stable conditions near the ground, with turbulence generation in the high-shear vicinity of a nocturnal jet towards the top of a Nocturnal Boundary Layer (NBL) - these hypotheses are explored in Sect. 4.3 where individual profiles are scaled and compared with other similarity results.

The onset of convective mixing after sunrise at 07:01 is shown by regular enhancements in the up- and downdraughts in the vertical Doppler velocity, and increased variance propagating upwards. The variance decreases from 16:00 onwards (sunset was at 16:26) and only a small amount of turbulent mixing is observed in the lowest range gates from then onwards, extending up to the BT Tower from approx. 22:00 onwards. In contrast, a ground-based aerosol layer forms from approx. 18:00 onwards, with a distinct layer of depth 400-600 m from 21:00. Whilst the aerosol and mixing heights are of similar height by day during the wellmixed Convective Boundary Layer (CBL), they diverge at night which can influence transport of particulates emitted at ground level up to the BT Tower, which may be "decoupled" from the surface if it sits above the turbulent layer (Dall'Osto et al., 2010).

In contrast, 7 November 2007 (Fig. 4b) was predominantly overcast due to a shallow layer of stratocumulus (shown by enhanced backscatter at c. $1 \mathrm{~km}$ ) and mean wind-speed was above-average $\left(7.4 \mathrm{~m} \mathrm{~s}^{-1}\right)$. A tracer experiment took place on this day and is reported in Martin et al. (2009). Overnight, from 00:00 onwards the aerosol layer persists but deepens and weakens from c. 04:00 onwards. A ground-based turbulent layer persists up to heights between 200 and $500 \mathrm{~m}$, which mixes and dilutes aerosols through its depth. Daytime convective mixing occurred throughout the whole boundary layer from c. 11:00 until 15:00, and was replaced by a ground-based turbulent layer, driven by wind shear. In contrast to 6 November, the cloud layer overnight reduces radiative cooling, and thus the stability is likely to be near-neutral and turbulence is thus not suppressed. Another feature is a layer of mixing beneath the clouds, of depth c. 300-500 $\mathrm{m}$, most clearly seen during night-time periods. Such turbulence, driven by downward convection to due to cloud-top radiative cooling in shallow stratocumulus, has been observed using Doppler lidar by Hogan et al. (2009) and could mix down particulates persisting at higher levels which may have undergone chemical reactions within the cloud. Numerous examples of cloud-driven turbulent layers were observed during REPARTEE, and will be reported separately in a future publication.
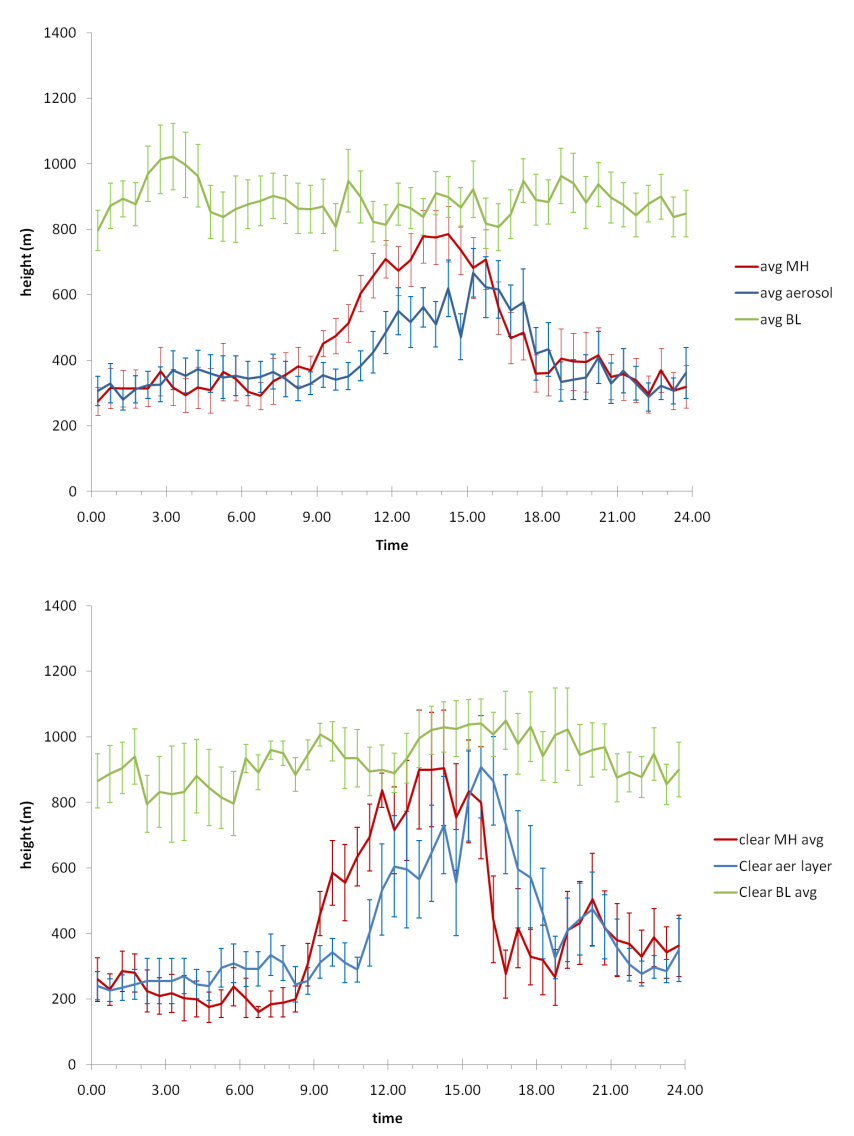

Fig. 5. Averages of derived boundary layer top (BL), aerosol layer (aerosol) and mixing height (MH) for diurnal cycle during REPARTEE II. Error bars show standard error. (a) all periods, (b) clear sky periods only.

\subsection{Mixing height variability}

Mixing height $z_{\mathrm{MH}}$, and aerosol layer height $z_{\mathrm{AER}}$, and boundary layer depth $z_{\mathrm{BL}}$, based on backscatter, were determined for all periods, and the mean time series are shown in Fig. 5a (standard error of the mean as error bars). It can be seen that $z_{\mathrm{BL}}$ is relatively invariant and lies between 800 and $1000 \mathrm{~m}$. There is no significant difference between $z_{\mathrm{AER}}$ and $z_{\mathrm{MH}}$ by night; but by day $z_{\mathrm{MH}}$ appears to evolve $2-3 \mathrm{~h}$ earlier than $z_{\text {AER }}$. Note that sunrise occurred between 06:22 and 07:16 during the campaign period, thus it takes c. $2 \mathrm{~h}$ for $z_{\mathrm{MH}}$ to grow significantly after sunrise. Sunset occurs between 17:09 and 16:12, when both layers are in decline at similar rates. An apparent lag was also seen on occasion by Emeis and Schäfer (2006) when comparing mixing heights derived from sodar and ceilometer data. The instruments were separated by $10 \mathrm{~km}$, so differences in local surface energy balance could not be ruled out in that case, however the present results demonstrate the same effect, i.e. that the aerosol layer rises after the turbulent layer. A full discussion of possible mechanisms is included in Sect. 4.4. 

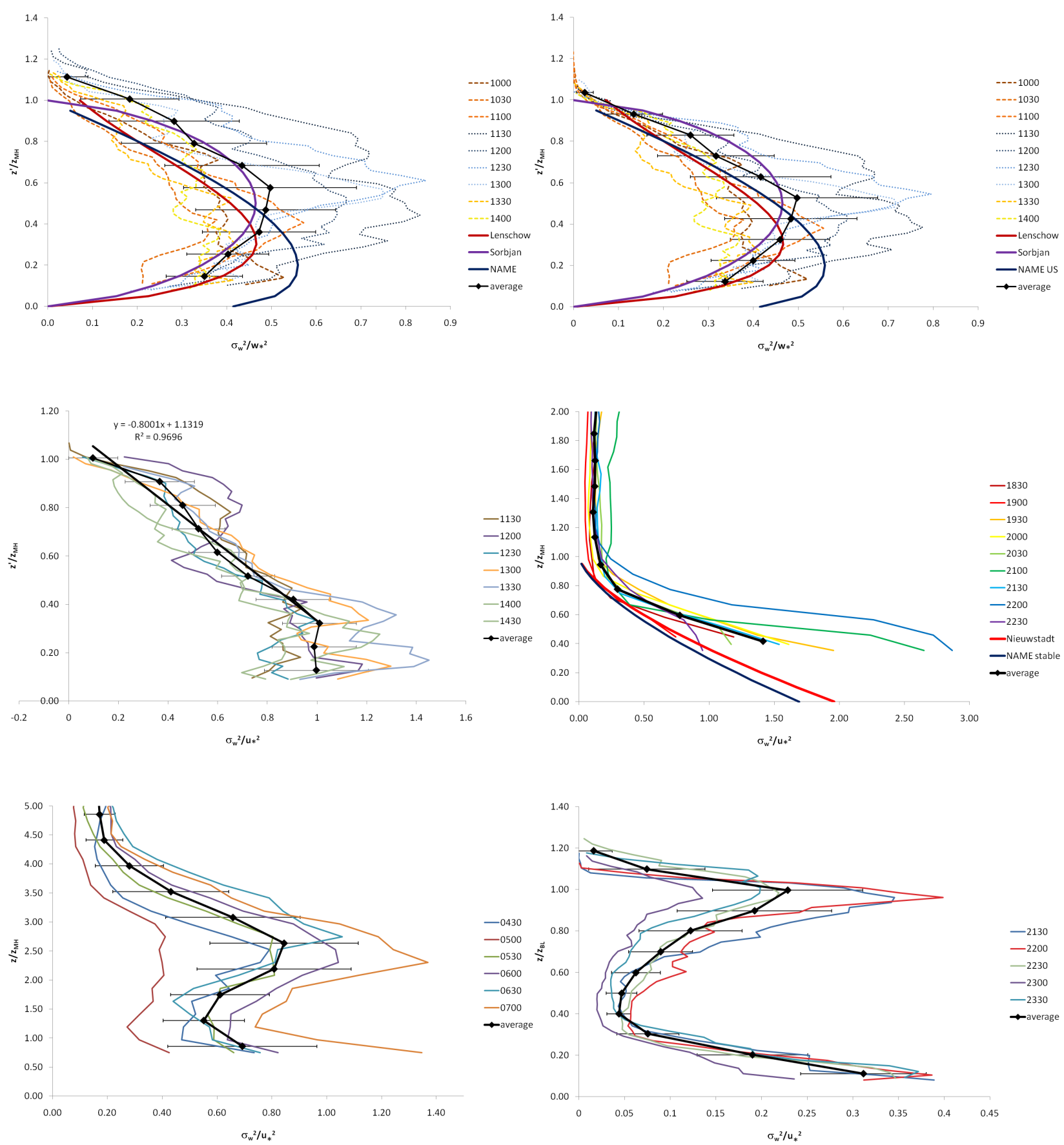

Fig. 6. Scaled profiles of vertical windspeed variance. (a) convective conditions. (b) convective conditions with rescaled height axis. (c) near neutral conditions with rescaled height axis. (d) stable conditions with rescaled height axis. (e) possible nocturnal jet profile. (f) cloud-topped night-time profile.

Figure $5 \mathrm{~b}$ shows the diurnal evolution of the mean heights of all layers for "clear sky" data (error bars indicate standard deviation). Several features can be observed: (1) as might be expected, there is larger diurnal range, with deeper layers occurring during the day through enhanced convective mixing, (2) from sunset (c. 17:00 onwards), $z_{\mathrm{MH}}$ reduces sharply, whereas the nocturnal aerosol layer takes longer to form, (3) later in the night (c. 00:00 onwards) $z_{\mathrm{MH}}$ appears to reduce whereas $z_{\mathrm{AER}}$ increases. Being careful to interpret the mean values from small numbers of datapoints, $z_{\mathrm{MH}}<z_{\mathrm{AER}}$ on $71 \%$ of occasions where clear sky data were available between 00:00 and 09:00. In contrast, during the day (09:00 to $17: 00$ ) on only $27 \%$ of occasions $z_{\mathrm{MH}}<z_{\mathrm{AER}}$, and in the period 17:00 to 00:00, $49 \%$ of occasions. So despite possible 
errors in determination of the heights, there seems to be a tendency during clear night-times for aerosol layers to propagate to higher heights than the classically defined mixing height, whereas in day-time this tendency is reversed.

\subsection{Boundary layer types and mixing profiles}

In this section, vertical profiles of $\sigma_{\text {wlidar }}^{2}$ during 6 and 7 November are grouped according to boundary layer state, scaled appropriately and compared with existing similarity results. The purpose is to test whether urban boundary layers display dissimilar characteristics to rural boundary layers, in particular whether night-time stable boundary layer features can be observed.

Figure 6 shows the scaled $\sigma_{w}^{2}$ profiles for different boundary layer states. All height co-ordinates have been corrected to allow for displacement height, i.e. $z^{\prime}=z-z_{d}$. Figure 6a shows the Convective Boundary Layer (CBL) during the day on 6 November, where the convective velocity scale, $w_{*}=\left\{g / T_{0} \overline{w^{\prime} T^{\prime}} z_{i}\right\}^{1 / 3}$ has been used. Surface temperature $T_{0}$ has been approximated by using the BT Tower measured sonic temperature (as this is converted to absolute temperature, this is an error of approximately $2 \%$ ); the surface temperature flux has been approximated by extrapolating the BT Tower measured heat flux to the ground, $\overline{w^{\prime} T^{\prime}} z=\overline{w^{\prime} T^{\prime}}{ }_{0}\left(1-1.2 z / z_{i}\right)$, as shown by Wood et al. (2010) to produce realistic mixed layer scaling. Mixing height, $z_{\mathrm{MH}}$, has been used to represent inversion height $z_{i}$. Overlaid are expressions by Lenschow et al. (1980), Sorbjan (1989), and an unstable profile used by the UK Met Office NAME dispersion model (Webster et al., 2003), calculated using mean values of $u_{*}$ and $w_{*}$ for the whole period.

It can be seen that the profiles are widely scattered, with profiles towards mid-day (in blue) showing larger values. Possible errors in the scaling variables are now explored. It can be seen that the profiles tend to small values at heights $z>z_{\mathrm{MH}}$, which may be due to a systematic underestimate in $z_{\mathrm{MH}}$. Using a definition of mixing height to be where $\sigma_{w}^{2} / w_{*}^{2}<0.05$, the profiles were rescaled using revised mixing height, $z_{\mathrm{MH}}^{\prime}$. The resulting profiles are shown in Fig. 6b: it can be seen that scatter has been slightly reduced. It is likely that remaining scatter is partly due to undersampling of the temperature flux by use of $30 \mathrm{~min}$ averages. Nevertheless, the mean profile exhibits a shape consistent with the Sorbjan (1989) and Lenschow et al. (1980) expressions. Wood et al. (2010) used an 18 month long dataset of BT Tower variance measurements and found a peak at $z \sim 0.3 z_{\mathrm{MH}}$, which agrees better with Lenschow et al. (1980). The unstable NAME profile (Webster et al., 2003) peaks further down due to addition of mixing due to shear stress: this appears to overestimate mixing near the surface.

Fig. $6 c$ shows profiles during the daytime on 7 November. On-site observations confirmed 7 or 8 oktas of stratocumu- lus throughout the day, and windy conditions, which tend to create near-neutral conditions. Scaling using $w_{*}$ (not shown) was not successful in reducing scatter, whereas $u_{*}$ was; this confirms that the boundary layer was near-neutral rather than significantly convective. Again, the scaling variables have been adapted: $u_{*}$ was extrapolated from BT Tower height to the surface using $u_{*}=u_{* 0}\left(1-z / z_{i}\right)$ where $z_{i}=z_{\mathrm{MH}}$. An overshoot of values for $z^{\prime}>z_{\mathrm{MH}}$ was observed, similar to Fig $6 \mathrm{a}$, and therefore the height-scale was revised to be where $\sigma_{w}^{2} / u_{*}^{2}<0.1$. The resulting plot in Fig. 6c shows a good collapse of profiles, particularly in the upper part of the boundary layer. A linear relationship fits very well $\left(R^{2}=0.97\right)$ to all but the lowest two points, similar to neutral boundary layer behaviour observed by Grant (1986), who observed monotonic decrease above $z / z_{i} \sim 0.2$. Extrapolating the linear relationship to the surface and taking the square root gives $\sigma_{w} / u_{*} \sim 1.19$, which is close the neutral result of $1.27 \pm 0.26$ determined by Roth (2000) for a variety of urban datasets. To sum up, the boundary layer properties appear to be close to other neutral case results; whether the lowest part of the profile $\left(z^{\prime} / z_{\mathrm{MH}}<0.4\right)$ being constant with height is distinctly urban is unclear.

The remaining figures depict night-time features. Figure $6 \mathrm{~d}$ shows the profiles for a "clear sky" period, from 18:30 to 23:00 on 6 November. As sunset was at 16:26, a transition period of 2 hours was estimated (Grant 1997) so periods from that time were excluded. A similar procedure was used to constrain mixing heights, i.e. $z_{\mathrm{MH}}^{\prime}$ taken to be where $\sigma_{w}^{2} / u_{*}^{2}<0.2$. This produced an average change in mixing height from $178 \mathrm{~m}$ to $262 \mathrm{~m}$, the largest fractional change in estimated mixing height, being approximately 3 lidar gates $(\sim 90 \mathrm{~m})$. The potential underestimate of lidar measured variance, as discussed in Sect. 3.1, could explain such an underestimate in mixing height during clear, calm night-time periods. Overlaid is the expression by Nieuwstadt (1984) based on stable boundary layer data at the Cabauw Tower in the Netherlands: it can be seen that the average profile follows a similar decrease with height, but is significantly larger. Apart from uncertainty in variance values due to the $30 \mathrm{~min}$ averaging period, the local BT Tower $u_{*}$ value has been used to scale the profiles: to produce agreement with the Nieuwstadt values, $u_{*}$ would have to be increased by $20 \%$. As the BT Tower during this period is very close to the mixing height, it is likely that the value is an underestimate of $u_{*}$ within the turbulent layer - anecdotally, turbulence at that height was observed to quiesce strongly on such clear nights, consistent with the sensor being in the residual layer above the Nocturnal Boundary Layer. Barlow et al. (2009) also observed periods where the BT Tower measurements may have been decoupled from the surface. Despite these uncertainties in the scaling parameters, the turbulent layer does seem to exhibit a form consistent with a stable boundary layer.

Figure 6e also shows profiles for a "clear sky" night-time period, but with radically different structure. The turbulent 
layer at the ground is still observed, but instead of decreasing with height above this, the turbulence increases again to a peak at approximately $2.5 z_{\mathrm{MH}}$. No corrections have been applied to the height data in this case. The minimum in turbulence at $z \sim 1.3 z_{\mathrm{MH}}$ is consistent with a nocturnal jet structure, where there is least shear near the jet maximum. Banta et al. (2006) observed very similar structure in $\sigma_{u}$ values using Doppler lidar, and it is reasonable to assume that $\sigma_{w}$ will exhibit similar structure. The appearance of a jet-type structure was highly unusual - this was the most prominent example, there being a much weaker, marginal case overnight on 1/2 November. Compared to the non-jet case in Fig. 6d, turbulent mixing was enhanced up to more than $5 z_{\mathrm{MH}}$.

Finally, Fig. 6f shows a cloudy night-time period on 7 November. Here, the most distinctive additional feature is the large peak in $\sigma_{w}$ observed in the upper part of the profile. Scaling the height axis with $z_{\mathrm{BL}}$ rather than $z_{\mathrm{MH}}$ produces better collapse of profiles at this height, giving a peak in turbulence at $z_{\mathrm{BL}} \sim 1$. It should be emphasised that this height is notionally proportional to cloud base, as the lidar signal is strongly attenuated at greater heights within the cloud. The profiles thus demonstrate the increase in mixing in the upper boundary layer due to stratiform clouds which extends down to $z \sim 0.4 z_{\mathrm{BL}}$, and appears to be distinct from the groundbased turbulent layer driven by wind shear. Radiative cooling at the top of the clouds determines the downward extent of the mixing (Hogan et al., 2009). It can be seen from Fig. $4 \mathrm{~b}$ that the backscatter is weak throughout the depth of the boundary layer for the same period, which is in stark contrast to the earlier part of the night, where clear conditions probably led to a stable boundary layer and strong layering of aerosols. As the wind-speed was near average during this period $\left(6.87 \mathrm{~m} \mathrm{~s}^{-1}\right)$, this emphasises the impact of stratiform clouds at night in (a) preventing stable layers from forming, and (b) potentially contributing to mixing throughout a significant depth of the boundary layer.

\subsection{Mixing timescales}

One of the aims of the REPARTEE campaign was to determine whether chemical transformations occur on the same timescales as urban turbulent transport timescales. Specifically, the meteorological observations are here used to estimate the timescale for turbulent transport from the surface up to the BT Tower where concurrent aerosol size distributions and composition were recorded (reported elsewhere in this issue).

Different time-scales can be defined to describe turbulence in the boundary layer (e.g. turbulent dissipation rate timescale, Verver et al., 1997). The time-scale that determines, for example, the potential for chemistry to occur between emission at ground level and the measurement level on the BT Tower is the average travel time of an inert scalar molecule between these heights. The far-field Lagrangian diffusivity for vertical turbulent transfer, $K$, is given by (Raupach, 1989):

$K(z)=\sigma_{w}^{2}(z) T_{L}(z)$

where $T_{L}$ is the Lagrangian timescale. If we adopt a simple resistance analogy for exchange of scalars with a surface, and assume for simplicity that momentum and scalar exchange are similar, then the effective aerodynamic resistance $r_{a}(z)$ can be calculated as (e.g. Thom, 1975):

$r_{a}(z)=\int_{z_{0}}^{z} \frac{1}{K(z)} d z$

where $z_{0}$ is the roughness length. A transport timescale that takes into account the integrated diffusivity can be defined as

$\tau_{t}(z)=\gamma r_{a}(z) z$

where $z$ is the height up to which material is mixed, and $\gamma$ is a coefficient, initially assumed to be 1 .

Profiles of $\sigma_{w}$ and $T_{L}$ as used in the current version of the UK Met Office NAME dispersion model (Webster et al., 2003) were adopted here. These profiles were formulated to reflect existing experimental and theoretical results but also to avoid discontinuities across changes in stability (Webster et al., 2003). Calculating $\sigma_{w}^{2}(z)$ and $T_{L}(z)$ required surface values of $H$ and $u_{*}$, which were estimated by extrapolating the local values measured at the BT Tower to the surface using the method described in Sect. 4.3. Local temperature measured at the BT Tower was used, as the results are relatively insensitive to temperature. Again, the inversion height $z_{i}$ was estimated using the observed mixing height, $z_{\mathrm{MH}}$.

Figure $7 \mathrm{a}$ shows the transport timescale $\tau_{t}$ for each $30 \mathrm{~min}$ period throughout the campaign when lidar and sonic data were available ( 372 periods). Also shown are the median, upper and lower quartile values for all data calculated for $3 \mathrm{~h}$ periods. This period was chosen to include reasonable numbers of data-points to provide more meaningful statistics. It can be seen that the most rapid transport times occur, not surprisingly, during the daytime, with the median value for the 12:00 to $15: 00$ period being $2580 \mathrm{~s}$. There is a relatively small increase in median values at night (18:00 to 03:00) compared to day (09:00 to 15:00) of 16\%. Notice, however, that much longer values occur during more stable night-time conditions when negative buoyancy suppresses vertical mixing. This is more clearly seen in Fig. 7b which shows $\tau_{t}$, normalised by its near-neutral value ( $3107 \mathrm{~s}$, for $\left|z^{\prime} / L\right|<0.1$ based on estimated surface fluxes) as a function of MoninObukhov stability parameter $z^{\prime} / L$.

We next consider whether the calculated magnitude of $\tau_{t}$ is indeed realistic. $\tau_{t}$ was therefore calculated for 26 October 2006, when a tracer release experiment was conducted at the same location (Martin et al., 2009). Tracer was released for $59 \mathrm{~min}$ at $z=0.39 \mathrm{~m}$ at a location $\sim 1300 \mathrm{~m}$ upstream of the BT Tower. Samples were taken at various locations, including the top of the BT Tower, with a time resolution of 


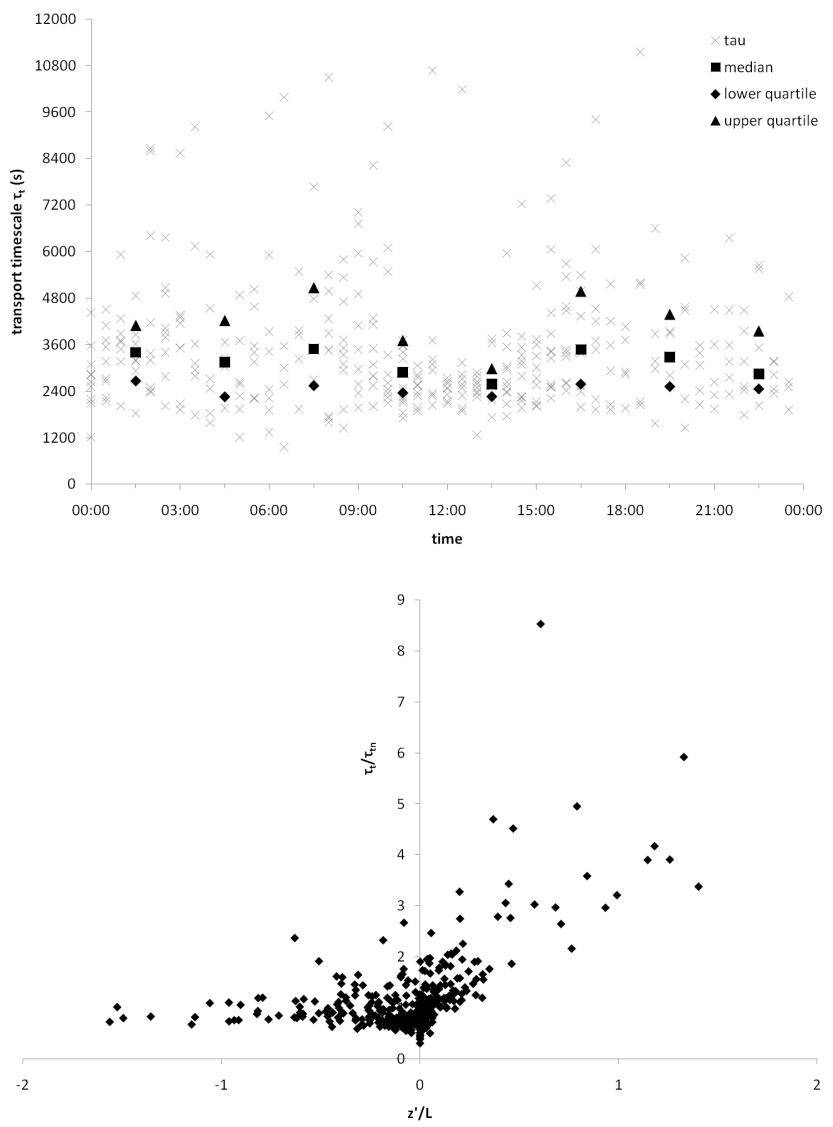

Fig. 7. Transport timescale $\tau_{t}$ calculated for REPARTEE II. (a) diurnal cycle throughout campaign. Median, upper and lower quartile values calculated over $3 \mathrm{~h}$ periods also shown. (b) $\tau_{t}$ normalised by near neutral value $\left(\left|z^{\prime} / L\right|<0.1\right)$ as a function of Monin-Obukhov stability parameter z'/L.

9 min sampling time per bag (plus 1 min change-over time), repeated 6 times throughout the hour. A finite amount of tracer was detected at the top of the BT Tower in the first sample for each repeated experiment, i.e. within $9 \mathrm{~min}$ of the initial release. This gives an estimate of $540 \mathrm{~s}$ for the vertical transport timescale. On this day the mean wind-speed was $12.3 \mathrm{~m} \mathrm{~s}^{-1}$, conditions were near neutral, and assuming typical values for roughness length of $0.75 \mathrm{~m}$ and displacement height, $z_{d}$, of $5 \mathrm{~m}, \tau_{t}$ was calculated to be $2654 \mathrm{~s}$. This is a factor of 5 longer than the observations, suggesting that $\gamma$ $\sim 0.2$, giving a median daytime value for the REPARTEE II campaign of $516 \mathrm{~s}$. This result should be treated cautiously as only one tracer experiment has been used to determine $\gamma$, and there is no theoretical basis for its value. However, it gives a near neutral estimate of $\sim 10 \mathrm{~min}$ for turbulent transport by diffusion up to the BT Tower, increasing to $\sim 20$ to 50 min for typical stable conditions, according to Fig. $7 \mathrm{~b}$.

To address the issue of non-passive scalars, these timescales need to be compared to relevant chemical timescales. One such approach is use of the dimensionless
Damköhler number which corresponds to the ratio of a given chemical time scale and turbulent time scale $N_{D} \equiv \frac{\tau_{t}}{\tau_{c}}$ such that if $N_{D}$ is $<1$ then there is little chemical transformation during turbulent transport. Given the turbulent transport times up to the BT Tower, particularly at night-time, there may be sufficient time for e.g. a strong interaction between gaseous $\mathrm{HNO}_{3}, \mathrm{NH}_{3}$ and aerosol $\mathrm{NH}_{4} \mathrm{NO}_{3}$ which would produce vertical fluxes that are strongly height dependent, putting certain experimental methodologies in doubt. The timescales presented here will allow better interpretation of such urban aerosol composition data sets in future.

Whilst the estimated timescales do quantify the time to mix particles upwards, they do not appear to explain the effect observed in Sect. 4.2, namely that the aerosol layer deduced from backscatter rises $1-2 \mathrm{~h}$ after the turbulent layer: the timescales are too short, even if the layer through which the boundary layer grows is assumed to be stable. One hypothesis which will be explored in future work for the current data-set is that humidity significantly affected growth of hygroscopic aerosol particles, leading to changes in backscatter (e.g. Gibert et al., 2007). Given the range of humidity experienced at the BT Tower (see Fig. 2b: range from c. 50\% to $100 \%$ ) it is likely that aerosol particles were affected by humidity changes, which could have led to changes in backscatter gradient and consequently yielded spurious aerosol layer heights.

\section{Conclusions}

During the second REPARTEE Intensive Observation Period in October/November 2007 a pulsed Doppler lidar was deployed in vertical stare mode in central London with the aim of determining boundary layer structure and its impact on vertical mixing of passive scalars from the surface. In combination with a sonic anemometer deployed on the $190 \mathrm{~m}$ BT Tower, the 3 week long data-set allowed determination of boundary layer depth, mixing timescales, and turbulent structure under a wide range of stability conditions given the unusually high pressure and large number of clear sky periods.

Comparison of the standard deviation of vertical velocity measured by the nearest lidar gate to the BT Tower height with sonic anemometer data showed a near one-to-one relationship when the sonic data was averaged to the same sampling frequency as the lidar. The agreement between the instruments was generally good but the lidar's limited sampling frequency $(0.278 \mathrm{~Hz})$ led to occasional underestimates of turbulent mixing especially during periods when the turbulence scales were smaller.

Lidar backscatter gradient and variance profiles were used to determine aerosol layer, $z_{\mathrm{AER}}$, and mixing height $z_{\mathrm{MH}}$, respectively. Typical maximum daytime $z_{\mathrm{MH}} \sim 700-800 \mathrm{~m}$, and $300-400 \mathrm{~m}$ at night. Under clear skies, the range increased to $750-850 \mathrm{~m}$ by day, and between $200-400 \mathrm{~m}$ at 
night. The sensitivity of the derived heights to the threshold criteria was tested: $z_{\mathrm{MH}}$ derived from the variance profile proved more robust. Consistent differences between $z_{\text {AER }}$ and $z_{\mathrm{MH}}$ were observed, particularly during clear nights. $z_{\mathrm{AER}}$ appeared to lag approximately two hours behind $z_{\mathrm{MH}}$ in growth and decay, however this conclusion may be sensitive to the aerosol layer algorithm used and whether humidity profiles led to changes in backscatter due to hygroscopic aerosol growth. These results are generally in agreement with other results (e.g. Pearson et al., 2010) in highlighting the utility of Doppler lidars in providing a direct measurement of the mixing height, and the difficulties in interpreting heights derived from backscatter given its dependence on effective aerosol radius as well as vertical distribution.

Qualitatively, both the backscatter and variance data show a rich variety of boundary layer structure and processes at high spatial and temporal resolution. Quantitatively, the vertical velocity variance data for selected periods during 6 and 7 November 2007 were scaled using mixing height and either $u_{*}$ or $w_{*}$ as appropriate and compared with established results for convective, neutral and stable boundary layers. The results seemed to be insensitive to the estimated error in mixing height, and the fluxes measured at the BT Tower were extrapolated to the surface to provide estimates of the scaling variables. The convective boundary layer structure agreed reasonably well with Sorbjan (1989) and Lenschow et al. (1980)'s expressions with a large maximum mid-boundary layer. Similarly, neutral boundary layer structure was similar to Grant (1986), with a relatively deep layer at the surface $\left(z \leq 0.4 z_{\mathrm{MH}}\right)$ with near constant variance. Whether this can be associated with the enhanced mechanical production of turbulence in a deep urban roughness sublayer requires more detailed analysis. Collapse to stable formulations was less successful, although the general form was similar. This can be attributed to the difficulties in measuring variance profiles under stable conditions, and making a robust estimate of surface fluxes from the BT Tower measurement height of $190 \mathrm{~m}$. Overall, the urban boundary layer structure in this limited number of cases appears similar to canonical boundary layers - a longer term data-set is clearly required to test whether specific urban characteristics exist.

Interesting deviations from canonical profiles were observed during night-time periods. During the later part of a clear, calm night, evidence was seen for a nocturnal jet in the variance profile. This was an unusual event, occurring only once strongly during the campaign. This suggests that stable layers do form over London, and can lead to decoupling of turbulence between the surface and the air above, but are relatively rare, in agreement with the observations of Barlow et al. (2009) during the DAPPLE campaign, and Wood et al. (2010)'s analysis of 18 months of BT Tower data. During a cloudy night-time period, in addition to a turbulent layer near the ground, a thick layer of enhanced turbulence was observed below the cloud, down to a depth of $z \sim 0.4 z \mathrm{BL}$. This was thought to be downward convection, triggered by stratocumulus radiative cooling at cloud top (Hogan et al., 2009). Such complex night-time turbulent structures should be taken into account when considering both locally sourced and long range transport of pollutants in urban atmospheres.

Given the general agreement between the variance profiles and existing formulations, parameterised profiles as used in the UK Met Office's NAME dispersion model (Webster et al., 2003) were used to calculate transport timescale $\tau_{t}$ from the surface up to the BT Tower throughout the campaign. Median values during the daytime were typically $\sim 2500 \mathrm{~s}$, rising by $\sim 16 \%$ at night. Comparing calculated $\tau_{t}$ with a tracer experiment performed during the first REPARTEE campaign (Martin et al., 2009), the estimated timescales seemed to be 5 times too large. Using this "calibration", the typical daytime transport timescale was $\sim 10 \mathrm{~min}$, rising to between $\sim 20$ and $50 \mathrm{~min}$ at night, depending on stability. These timescales are important to determine in relation to physico-chemical processes occurring on a similar timescale, such as the evaporation of semi-volatile ultrafine particles, a process observed in the REPARTEE data (Dall'Osto et al., 2010).

These results show that Doppler lidars are highly useful tools in probing urban boundary layer structure. The results for London show some evidence of decoupled turbulence and aerosol layers during night-time. Measurements using both BT Tower sonic anemometer and Doppler lidar are continuing under the EPSRC-funded Advanced Climate Technology Urban Atmospheric Laboratory (ACTUAL) project (www.actual.ac.uk), and year-long observations of pollutant gases, particulates and boundary layer structure across London are planned through the NERC-funded ClearfLo project (www.clearflo.ac.uk).

Acknowledgements. This work was funded by the BOC Foundation and a NERC PhD studentship (T. Dunbar). The Salford Doppler lidar is part of the National Centre for Atmospheric Science (NCAS) Facility for Ground-based Atmospheric Measurement (FGAM). We would particularly like to thank Guy Pearson and Justin Eacock of Halo Photonics who helped set up the lidar. We are also grateful to the University of Westminster for offering space to deploy the lidar.

Edited by: W. T. Sturges

\section{References}

Al-Jiboori, M. H., Xu, Y., and Qian, Y.: Local similarity relationships in the urban boundary layer, Bound.-Layer Meteorol., 102, 63-82, 2002.

Angevine, W. M., White, A. B., Senff, C. J., Trainer, M., Banta, R. M., and Ayoub, M. A.: Urban-rural contrasts in mixing height and cloudiness over Nashville in 1999, J. Geophys. Res., 108(D3), 4092, doi:10.1029/2001JD001061, 2003.

Argentini, S., Mastrantonio, G., and Lena, F.: Case studies of the wintertime convective boundary-layer structure in the urban area of Milan, Italy, Bound.-Layer Meteorol., 93(2) 253-267, 1999. 
Banta, R. M., Senff, C. J., White, A. B., Trainer, M., McNider, R. T., Valente, R. J., Mayor, S. D., Alvarez, R. J., Hardesty, R. M., Parrish, D., and Fehsenfeld, F. C.: Daytime buildup and nighttime transport of urban ozone in the boundary layer during a stagnation episode, J. Geophys. Res., 103(D17), 22519-22544, 1998.

Banta, R. M., Pichugina, Y. L., and Brewer, W. A., Turbulent velocity-variance profiles in the stable boundary layer generated by a nocturnal low-level jet, J. Atmos. Sci., 63, 2700-2719, 2006.

Barlow, J. F., Rooney, G. G., von Hunerbein, S., and Bradley, S. G.: Relating urban surface layer structure to upwind terrain for the Salford experiment (Salfex), Bound. Layer Meteorol., 127(2), 173-191, 2008.

Barlow, J. F., Dobre, A., Smalley, R. J., Arnold, S. J., Tomlin, A. S., and Belcher, S. E.: Referencing of street-level flows: results from the DAPPLE 2004 campaign in London, UK, Atmos. Environ., 43, 5536-5544, 2009.

Bozier, K. E., Pearson, G. N., and Collier, C. G.: Doppler lidar observations of Russian forest fire plumes over Helsinki, Weather, 62(8), 203-208, 2007

Calhoun, R., Heap, R., Princevac, M., Newsom, R., Fernando, H., and Ligon, D.: Virtual towers using coherent Doppler lidar during the Joint Urban 2003 dispersion experiment, J. Appl. Meteorol. Climatol., 45, 1116-1126, 2006.

Casadio, S., DiSarra, A., Fiocco, G., Fua, D., Lena, F., and Rao, M. P.: Convective characteristics of the nocturnal urban boundary layer as observed with Doppler sodar and Raman lidar, Bound.Layer Meteorol., 79(4), 375-391, 1996.

Chen, W. B., Kuze, H., Uchiyama, A., Suzuki, Y. and Takeuchi, N.: One-year observation of urban mixed layer characteristics at Tsukuba, Japan using a micro pulse lidar, Atmos. Environ., 35(25), 4273-4280, 2001.

Collier, C. G., Davies, F., Bozier, K. E., Holt, A. R., Middleton, D. R., Pearson, G. N., Siemen, S., Willetts, D. V., Upton, G. J. G., and Young, R. I.: Dual-doppler lidar measurements for improving dispersion models, B. Am. Meteorol. Soc., 86, 825838,2005

Cooper, D. I. and Eichinger, W. E.: Structure of the atmosphere in an urban planetary boundary-layer from lidar and radiosonde observations, J. Geophys. Res., 99(D11), 22937-22948, 1994.

Cros, B., Durand, P., Cachier, H., Drobinski, P., Frejafon, E., Kottmeier, C., Perros, P. E., Peuch, V. H., Ponche, J. L., Robin, D., Said, F., Toupance, G., and Wortham, H.: The ESCOMPT program: an overview, Atmos. Res., 69(3-4), 241-279, 2004.

Dall'Osto, M., Thorpe, A., Beddows, D. C. S., Harrison, R. M., Barlow, J. F., Dunbar, T. M., Williams, P. I., and Coe, H.: Remarkable dynamics of nanoparticles in the urban atmosphere, Atmos. Chem. Phys. Discuss., 10, 30651-30689, doi:10.5194/acpd-1030651-2010, 2010.

Darby, L. S., Allwine, K. J., and Banta, R. M.: Nocturnal low-level jet in a mountain basin complex. Part II: Transport and diffusion of tracer under stable conditions, J. Appl., Meteorol. Climatol., 45(5), 740-753, 2006.

Davies, F., Middleton, D. R., and Bozier, K. E.: Urban air pollution modelling and measurements of boundary layer height, Atmos. Environ., 41, 4040-4049, 2007.

Del Guasta, M.: Daily cycles in urban aerosols observed in Florence (Italy) by means of an automatic 532-1064nm lidar, Atmos. Environ., 36(17), 2853-2865, 2002.

Dupont, E., Menut, L., Carissimo, B., Pelon, J., and Flamant, P.:
Comparison between the atmospheric boundary layer in Paris and its rural suburbs during the ECLAP experiment, Atmos. Environ., 33(6), 979-994, 1999.

Emeis, S.: Vertical wind profiles over an urban area, Meteorologische Zeitschrift, 13(5), 353-359, 2004.

Emeis, S. and Schäfer, K.: Remote sensing methods to investigate boundary-layer structures relevant to air pollution in cities, Bound. Layer Meteorol., 121, 377-385, 2006.

Emeis, S. and Turk, M.: Frequency distributions of the mixing height over an urban area from sodar data, Meteorologische Zeitschrift, 13(5), 361-367, 2004.

Emeis, S., Münkel, C., Vogt, S., Müller, W. J., and Schäfer, K.: Atmospheric boundary-layer structure from simultaneous SODAR, RASS, and ceilometer measurements, Atmos. Environ. 38, 273 286, 2004.

Emeis, S., Baumann-Stanzer, K., Piringer, M., Kallistratova, M., Kouznetsov, R., and Yushkov, V.: Wind and turbulence in the urban boundary layer - analysis from acoustic remote sensing data and fit to analytical relations, Meteorologische Zeitschrift, 16(4), 393-406, 2007.

Emeis, S., Schäfer, K. and Münkel, C.: Surface-based remote sensing of the mixing-layer height - a review, Meteorologische Zeitschrift, 17(5), 621-630, 2008.

Ferretti, R., Mastrantonio, G., Argentini, S., Santoleri, R., and Viola, A.: A model-aided investigation of winter thermally driven circulation on the Italian Tyrrhenian coast: a case study, J. Geophys. Res., 108(D24), 4777, doi:10.1029/2003JD003424, 2003.

Georgoulias, A. K., Papanastasiou, D. K., Melas, D., Amiridis, V., and Alexandri, G.: Statistical analysis of boundary layer heights in a suburban environment, Meteorol. Atmos. Phys., 104(1-2), 103-111, 2009.

Grant, A. L. M.: An observational study of the evening transition boundary-layer, Q. J. Roy. Meteorol. Soc., 123, 657-677, 1997.

Grant, A. L. M.: Observations of boundary layer structure made during the 1981 KONTUR experiment, Q. J. Roy. Meteorol. Soc., 112, 825-841, 1986.

Guinot, B., Roger, J. C., Cachier, H., Wang, P. C., Bai, J. H., and Tong, Y.: Impact of vertical atmospheric structure on Beijing aerosol distribution, Atmos. Environ., 40(27), 5167-5180, 2006.

Han, S. Q., Bian, H., Tie, X. X., Xie, Y. Y., Sun, M. L. and Liu, A. X.: Impact of nocturnal planetary boundary layer on urban air pollutants: measurements from a $250 \mathrm{~m}$-tower over Tianjin, China, J. Hazardous Materials, 162(1), 264-269, 2009.

Harrison, R. M., DallOsto, M., Thorpe, A. J., Allan, J., Coe, H., Dorsey, J., Gallagher, M., Martin, C., Whitehead, J., Williams P., Benton, A. K., Jones, R. L., Langridge, J., Ball, S., Langford, B., Hewitt, C. N., Davison, B., Martin, D., Petersson, K., Henshaw, S. J., White, I. R., Shallcross, D. E., Barlow, J. F., Dunbar, T., Davies, F., and Nemitz, E. G.:Atmospheric chemistry and physics in the atmosphere of a developed megacity (London): an overview of the REPARTEE experiment and its conclusions, in preparation, 2011

He, Q. S., Mao, J. T., Chen, J. Y., and Hu, Y. Y.: Observational and modelling studies of urban atmospheric boundary-layer height and its evolution mechanisms, Atmos. Environ., 40(6), 1064 1077, 2006.

Helfter, C., Famulari, D., Phillips, G. J., Barlow, J. F., Wood, C. R., Grimmond, C. S. B., and Nemitz, E.: Controls of carbon dioxide concentrations and fluxes above central London, Atmos. Chem. 
Phys. Discuss., 10, 23739-23780, doi:10.5194/acpd-10-237392010, 2010.

Hogan, R. J., Grant, A. L. M., Illingworth, A. J., Pearson, G. N. and O'Connor, E. J.: Vertical velocity variance and skewness in clear and cloud-topped boundary layers as revealed by Doppler lidar, Q. J. Roy. Meteorol. Soc., 135, 635-643, 2009.

Kallistratova, M., Kouznetsov, R. D., Kuznetsov, D. D., Kuznetsova, I. N., Nakhaev, M., and Chirokova, G.: Summertime low-level jet characteristics measured by sodars over rural and urban areas, Meteorologische Zeitschrift, 18(3), 289-295, 2009.

Klein, P. and Clark, J. V.: Flow variability in a north American downtown street canyon, J. Appl. Meteorol. Climatol., 46, 851877, 2007.

Kolev, I., Savov, P., Kaprielov, B., Parnanov, O., and Simeonov, V.: Lidar observations of the nocturnal boundary layer formation over Sofia, Bulgaria, Atmos. Environ., 34(19), 3223-3235, 2000.

Langford, B., Nemitz, E., House, E., Phillips, G. J., Famulari, D., Davison, B., Hopkins, J. R., Lewis, A. C., and Hewitt, C. N.: Fluxes and concentrations of volatile organic compounds above central London, UK, Atmos. Chem. Phys., 10, 627-645, doi:10.5194/acp-10-627-2010, 2010.

Lemonsu, A., Bastin, S., Masson, V., and Drobinski, P.: Vertical structure of the urban boundary layer over Marseille under seabreeze conditions, Bound.-Layer Meteorol., 118(3), 477-501, 2006.

Lenschow, D. H., Wyngaard, J. C., and Pennell, W. T.: Mean-field and second moment budgets in a baroclinic, convective boundary layer, J. Atmos. Sci. 37, 1313-1326, 1980.

Liu, H. P., Chan, J. C. L., and Cheng, A. Y. S.: Internal boundary layer structure under sea-breeze conditions in Hong Kong, Atmos. Environ., 35(4), 683-692, 2001.

Lock, A. P., Brown, A. R., Bush, M. R., Martin, G. M., and Smith, R. N. B.: A new boundary layer mixing scheme. Part I: scheme description and single-column model tests, Mon. Weather Rev., 128, 3187-3199, 2000.

Martin, C. L.: Transportation and transformation of urban aerosol particles, PhD. Thesis, University of Manchester, Manchester, UK, 2009.

Martin, D., Petersson, K. F., White, I. R., Henshaw, S. J., Nickless, G., Lovelock, A., Barlow, J. F., Dunbar, T., Wood, C. R., and Shallcross, D. E.: Tracer concentration profiles measured in central London as part of the REPARTEE campaign, Atmos. Chem. Phys., 11, 227-239, doi:10.5194/acpd-11-227-2011, 2011.

Menut, L., Vautard, R., Flamant, C., Abonnel, C., Beekmann, M., Chazette, P., Flamant, P. H., Gombert, D., Guedalia, D., Kley, D., Lefebvre, M. P., Lossec, B., Martin, D., Megie, G., Perros, P., Sicard, M., and Toupance, G.: Measurements and modelling of atmospheric pollution over the Paris area: an overview of the ESQUIF project, Ann. Geophys., 18(11), 1467-1481, doi:10.5194/angeo-18-1467-2000, 2000.

Met Office Monthly climate summary for October 2007, http: //www.metoffice.gov.uk/climate/uk/2007/october.html, last access: 18 August 2009, 2007.

Newsom, R. K., Ligon, D., Calhoun, R., Heap, R., Cregan, E., and Princevac, M.: Retrieval of microscale wind and temperature fields from single- and dual-Doppler lidar data, J. Appl., Meteorol., 44(9), 1324-1345, 2005

Nieuwstadt, F. T. M.: The turbulent structure of the stable, nocturnal boundary layer, J. Atmos. Sci., 41(14), 2202-2216, 1984.

Pearson, G. N., Davies, F., and Collier, C. G.: An analysis of the performance of the UFAM pulsed Doppler lidar for observing the boundary layer, J. Atmos. Ocean. Tech., 26, 240-250, 2009.

Pearson, G., Davies, F., and Collier, C.: Remote sensing of the tropical rain forest boundary layer using pulsed Doppler lidar, Atmos. Chem. Phys., 10, 5891-5901, doi:10.5194/acp-10-58912010, 2010.

Piringer, M. and Baumann, K.: Exploring the urban boundary layer by sodar and tethersonde, Phys. Chem. of the Earth, 26(11-12), 881-885, 2001.

Rao, M. P., Casadio, S., Fiocco, G., Cacciani, M., Di Sarra, A., Fua, D., and Castracane, P.: Estimation of atmospheric water vapour flux profiles in the nocturnal unstable urban boundary layer with Doppler sodar and Raman lidar, Boundary-layer Meteorol., 102(1), 39-62, 2002.

Raupach, M. R.: A practical Lagrangian method for relating scalar concentrations to source distributions in vegetation canopies, Q. J. R. Meteorol. Soc., 115, 609-632, 1989.

Reitebuch, O., Strassburger, A., Emeis, S., and Kuttler, W.: Nocturnal secondary ozone concentration maxima analysed by sodar observations and surface measurements, Atmos. Environ., 34(25), 4315-4329, 2000.

Roth, M.: Review of atmospheric turbulence over cities, Q. J. Roy. Meteorol. Soc. 126, 941-990, 2000.

Rye, B. J. and Hardesty, R. M.: Discrete spectral peak estimation in incoherent backscatter heterodyne lidar. II: correlogram accumulation, IEEE Trans. Geosci. Remote Sens., 31, 28-35, 1993.

Seibert, P., Beyrich, F., Gryning, S.-E., Joffre, S., Rasmussen, A., and Tercier, P.: Review and intercomparison of operational methods for the determination of the mixing height, Atmos. Environ., 34, 1001-1027, 2000.

Sorbjan, Z.: Structure of the atmospheric boundary layer. Prentice Hall, New Jersey, USA, 1989.

Spanton, A. M. and Williams, M. L.: A comparison of the structure of the atmospheric boundary layers in central London and a rural/suburban site using acoustic sounding, Atmos. Environ., 22(2), 211-223, 1988.

Thom, A. S.: Momentum, mass and heat exchange of plant communities. In: Vegetation and the Atmosphere, Vol. 1, Academic Press, 1975.

Uno, I., Wakamatsu, S., Ueda, H., and Nakamura, A.: Observed structure of the nocturnal urban boundary layer and its evolution into a convective mixed layer, Atmos. Environ., 26(1), 45-57, 1992.

Vakeva, M., Hameri, K., Puhakka, T., Nilsson, E. D., Hohti, H., and Makela, J. M.: Effects of meteorological processes on aerosol particle size distribution in an urban background area, J. Geophys. Res., 105(D8), 9807-9821, 2000.

Verver, G. H. L., Van Dop, H., and Holtslag, A. A. M.: Turbulent mixing of reactive gases in the convective boundary layer, Bound.-Layer Meteorol., 85, 197-222, 1997.

Vesala, T., Jarvi, L., Launiainen, S., Sogachev, A., Rannik, U., Mammarella, I., Siivola, E., Keronen, P., Rinne, J., Riikonen, A. and Nikinmaa, E.: Suface-atmosphere interactions over complex urban terrain in Helsinki, Finland, Tellus B - Chem. Phys. Meteorol., 60(2), 188-189, 2008.

Webster, H. N., Thomson, D. J., and Morrison, N. L.: New turbulence profiles for NAME, UK Met Office Turbulence and Diffu- 
sion Note No. 288, 2003.

Wilczak, J. M., Oncley, S. P., and Stage, S. A.: Sonic anemometer tilt correction algorithms, Bound.-Layer Meteorol., 99, 127-150, 2001.

Wood, C. R., Lacser, A., Barlow, J. F., Padhra, A., Belcher, S. E., Nemitz, E., Helfter, C., Famulari, D., and Grimmond, C. S. B.: Turbulent flow at 190 metres above London during 2006-2008: a climatology and the applicability of similarity theory, Bound.Layer Meteorol., 137, 77-96, 2010.
Ziomas, I. C.: The Mediterranean campaign of photochemical tracers transport and chemical evolution (MEDCAPHOT-TRACE): an outline, Atmos. Environ., 32(12), 2045-2053, 1998. 